\title{
A New Project-Based Curriculum of Design Thinking with Systems Engineering Techniques
}

\author{
Shinichiro Haruyama ${ }^{1}$, Sun K. Kim¹ ${ }^{1}$ Kurt A. Beiter ${ }^{2}$, Gerard P.J. Dijkema ${ }^{3}$, Olivier
} L. de Weck ${ }^{4}$

\begin{abstract}
${ }^{1}$ Graduate School of System Design and Management, Keio University, Yokohama, Japan ${ }^{2}$ Department of Mechanical Engineering, Stanford University, Stanford, California, U.S.A. ${ }^{3}$ Energy and Industry Group, Delft University of Technology, the Netherlands ${ }^{4}$ Department of Aeronautics and Astronautics and Engineering Systems Division, Massachusetts Institute of Technology, Cambridge, Massachusetts, U.S.A.
\end{abstract}

haruyama@sdm.keio.ac.jp, sunkim@sdm.keio.ac.jp, kbeiter@stanford.edu, G.P.J.Dijkema@tudelft.nl, deweck@mit.edu

\begin{abstract}
We developed a new education curriculum called "ALPS" (Active Learning Project Sequence) at Keio University that emphasizes team project-based learning and design thinking with systems engineering techniques. ALPS is a 6 month course, in which students work as a team and design and propose innovative systems. Students identify requirements, propose solution scenarios, and define competitive products or service systems. The multi-university faculty team consists of members of one Japanese university (Keio University), two US universities (Stanford University and MIT), and one European university (TU Delft). The faculty team members from these universities teach design thinking methods and systems engineering methods along $a$ "V model" roadmap. Each year, the university team announces a grand theme. The themes we announced so far were "Enhancing Senior Life in Japan" in 2008, "Creation of Sustainable Community" in 2009, "Safety and Security" in 2010, and "Symbiosis and Synergy" in 2011. Since 2010, the university team asked companies, government, and nonprofit organizations to propose a project based on the grand theme. Proposer organizations work with Keio University early on to define the project and define project requirements. At the end of the 6 months, the final deliverable is an in-depth analysis and recommendations on the problem, based on the latest insights developed at participating universities. By proposing an ALPS project, proposer organizations can encounter fresh, innovative ideas by the mixed student body of multinational/cultural/professional backgrounds and experience sophisticated system design methods.
\end{abstract}

Keywords. Design Thinking, Voice of Customers, Voice of Society, VModel, Active Learning, Team Project-based Learning, Scenario Development, Multi-disciplinary Teams 


\section{Introduction}

Traditional engineering has made great accomplishments in the 19th and 20th century. Examples are locomotives, automobiles, airplanes, electronics, modern medicines, etc. However, as systems became more and more complex in the $20^{\text {th }}$ century, the traditional engineering was not good enough to handle them. To deal with complex system problems, systematic approach was needed for such problems as urban planning, large-scale train network control, financial transaction system, space projects such as Apollo programs. Systems engineering is inherently interdisciplinary in order to handle a mix of various systems, and it includes control engineering, industrial engineering, organizational studies, project management, etc. One of the approaches of systems engineering uses a "V-model", which defines a procedure for developing complex systems. In the V-model, requirements for a system are first defined and then more detailed requirements are specified. After detailed requirements are completed, the system is designed and built. The system is then verified to check if the built system meets the defined requirements. After all the verifications are complete, validation is done by a customer who asked a developer to build the system. This systems engineering approach and the V-model procedure has been very successful for the developments of various products and services. However, many system developments still fail because they often do not meet customer requirements or needs. It turns out that even when systems engineering is becoming mature, the voice of customers or the voice of stakeholders is still very important and crucial for the success of any system development.

There have been a great deal of attentions regarding methodologies of customer value creation or design thinking, which is “a discipline that uses the designer's sensibility and methods to match people's needs with what is technologically feasible and what a viable business strategy can convert into customer value and market opportunity" (Brown, 2009). There have been several curriculums of design thinking in the world, such as d.school at Stanford University in the USA, i-school at Tokyo University in Japan, Innovation Design Engineering at Royal College of Art in United Kingdom, etc. Many of these curriculums emphasize the importance of user-centered design and experimentation, prototyping, and sustainability, etc. Design thinking has positive benefits such as better understanding on empathy and creation of better thinking models, etc.

Our purpose is to combine systems engineering methods with design thinking. We believe that design thinking methodologies are very effective for feeling empathy for stakeholders and for finding out what they need, and that systems engineering methods are very useful for designing complex systems once the requirement of the system is clarified and focused. ALPS curriculum was designed to teach both design thinking and systems engineering intermixed in one course. 


\section{Vision of ALPS}

We started ALPS at Keio University in 2008 (Ishii, 2009) and improved its contents for the past 4 years. The purpose of ALPS was to teach students how to create innovative services or products, while reinforcing the key concepts of design thinking and systems engineering. The key features of ALPS are team-based creation of ideas, design from the viewpoint of users, systematic approach from the idea creation phase, idea sharing and proposal using prototypes, and development of effective communication to express ideas. Each of the above features will be explained below.

\section{- Team-based creation of ideas}

We choose team-based learning, because we believe that team activity is a very effective way of learning. It will also bring increased responsibility for each individual. Each year, the class of ALPS is between 60 and 70 students, which consist of the mix of students with social science background and technical background. Over half of students have extensive practical experience, most of who are in the degree program while working for various companies and organizations. Each year, 12 to 14 student teams are formed based on the mix of following factors: 1) length of practical experience, 2) area of prior education and/or experience, and 3) gender. In 2011, we slightly changed a team forming policy and formed student teams based on the preference of projects by individual students.

- Design from the viewpoint of users

We emphasize the importance of the viewpoint of users rather than that of companies or service providers. We ask student teams to go out and listen to users when they start a project. Some of student teams ask questions at a nearby train station, and others observe the behavior of customers at a supermarket. We also ask them to listen to "voice of society" in order to find out what a society needs. Without knowing the viewpoint of users, student teams will never come up with good solutions.

- Systematic approach from the idea creation phase

Rather than asking students to create ad-hoc ideas, we teach them techniques of idea creation such as brain storming, six thinking hats, and TRIZ. By using these techniques, team members of each student group are able to generate more unique ideas.

- Idea sharing and proposal using prototypes

We ask student teams to make prototypes in order to share ideas among team members or show ideas to others. By making prototypes, students can make ideas tangible and make ideas more concrete. We do not ask students to make nice-looking prototypes. Instead, we ask them to make rough prototypes quickly so that they can exchange and share ideas at the early stages of idea creation. 
- Development of effective communication to express ideas

We ask students to do group presentations, where they not only show slides using PowerPoint, but also show prototypes to illustrate examples of how their idea can be applied. We also ask individual student to do an elevator pitch, which is a wellpracticed verbal presentation of an idea in the time it would take to ride up an elevator usually in one minute.

\section{Contents and Schedule of ALPS}

We wanted to introduce the key methods and tools that integrate into the basic system design and management process: the product development V-Model (Fig. 1). In selecting the learning modules to be covered in limited number of workshop sessions, we brainstormed to understand the background and needs of ALPS as well as our own competencies.

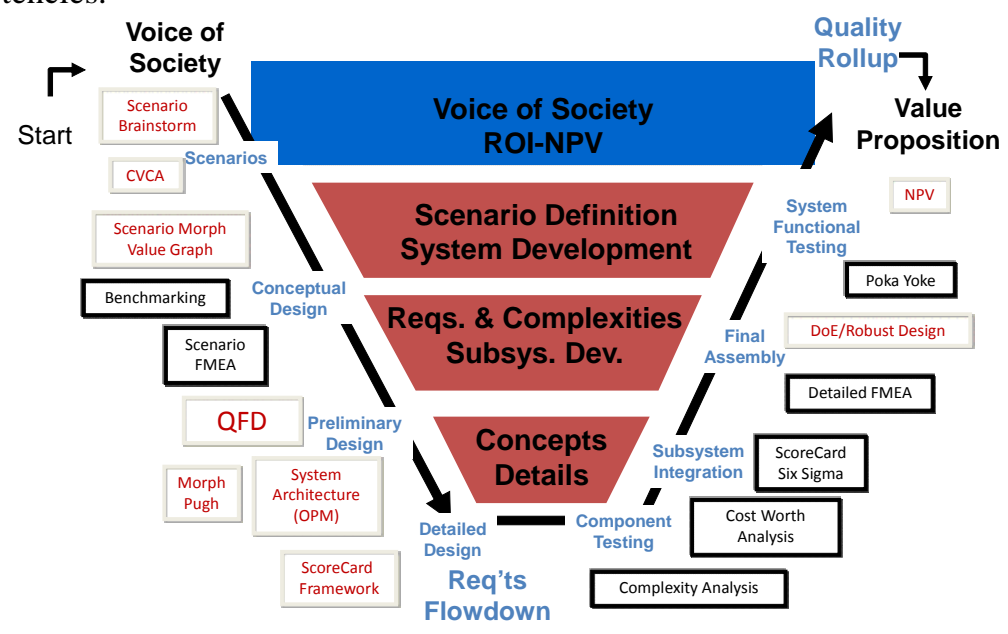

Fig. 1. Tools taught at ALPS in a V-Model of System Development Process

The figure shows the major methods and tools that authors incorporated in ALPS at Keio University. In particular, we focused on the planning and concept development stage. We focused on tools that have a track record in industry and are compatible with team project-based learning ((Dori, 2002; Donaldson, 2006; Beiter, 2006; Kim, 2008). We give the following lectures during the five workshop sequence. Each lecture included homework assignments to be applied to each team's project topic. For each workshop, we define at least one method for the team to initiate over night of the first day, and report back on the second day. ALPS instructional team scheduled five two-day workshops as shown in Fig. 2. 


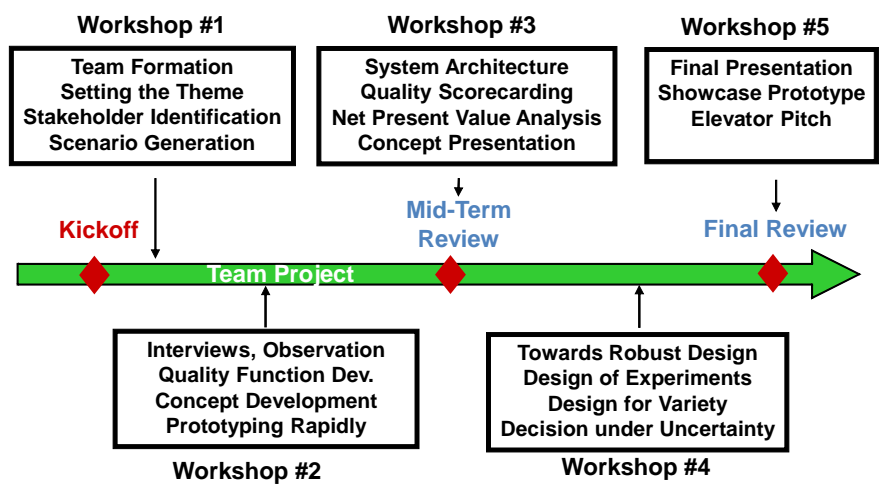

Fig. 2. Workshop Schedule and Learning Modules

\section{Methods and Tools taught at ALPS}

This section shows several methods and tools taught at ALPS, which are key components of design thinking and systems engineering.

\subsection{Customer Value Chain Analysis}

Customer value chain analysis (CVCA) (Donaldson, 2006) is a tool that enables design teams in the product definition phase to comprehensively identify pertinent stakeholders, their relationships with each other, and their role in the product's life cycle. CVCA is useful for the confirmation of the product's business model, the recognition of the critical stakeholders, and the clarification of the value proposition.

\subsection{Scenario Generation by Morphological Analysis}

When a new service or product is being designed, it is very useful to show what kind of scenario its service or product is being used. For that purpose, an appropriate scenario has to be set up, and morphological analysis is one of effective methods to generate scenarios. Morphological analysis (Zwicky, 1969) is a method for systematically structuring and investigating the total set of relationships in multidimensional problem complexes, which combines parameters into new combinations for the later review of the problem solver. A selection of parameters or attributes is chosen and combinations explored. Fig. 3 shows an example of Scenario-FunctionForm Morphology for Travel Assistant, where the morphological concept generation method guided them to several alternatives by listing the necessary functions that enable the solutions for such scenarios. 


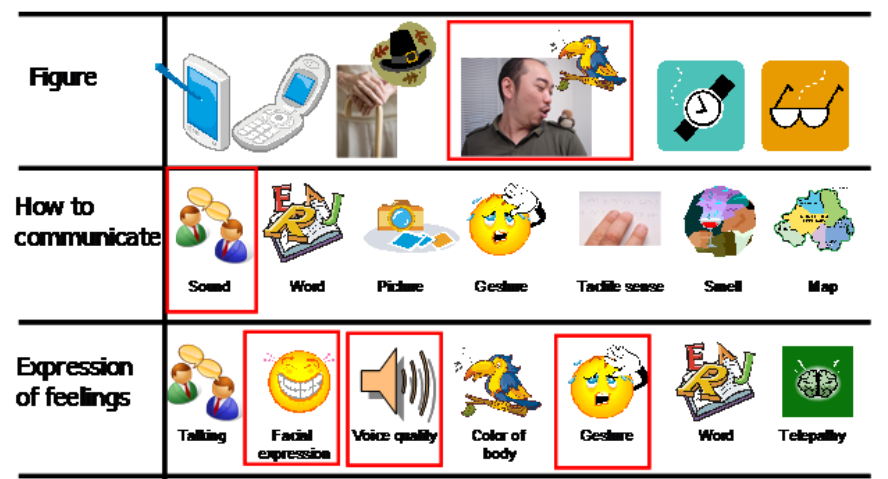

Fig. 3. Scenario-Function-Form Morphology for Travel Assistant (From ALPS 2008 Midterm Presentation, Team C1, Sept. 2008)

\subsection{Scenario Graph}

Scenario Graph (Kim, 2007) is used as a mind mapping tool that aids teams in fully brainstorming through different possible uses and situations and extract information in each of those scenarios. By linearly walking through each case, potential user locations (Where), activities associated with the location (What), people involved with the activities (Who), user circumstances (When), and the corresponding user state are revealed as shown in Fig. 4. The objective of scenario generation is to assist teams in discovering what customer needs exist in the scenarios relevant to their core competencies.

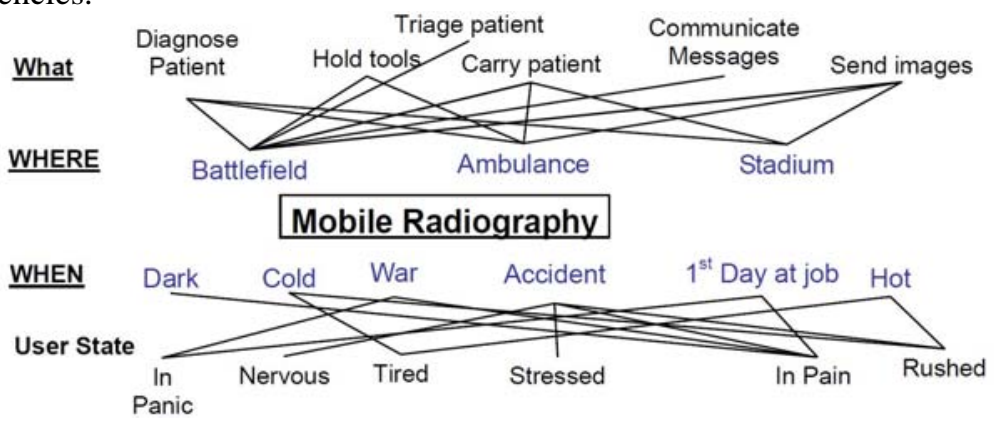

Fig. 4. Scenario Graph for Mobile Radiography Case (Kim, 2007)

\subsection{Pugh Concept Selection}

Pugh Concept Selection (Pugh, 1996) is very effective for comparing concepts that are not refined enough for direct comparison with the engineering requirements. The method is an iterative evaluation that tests the completeness and understanding of requirements, quickly identifies the strongest concept. ALPS students use this method in the early stages after they have multiple solutions for a problem. 


\subsection{Object Process Methodology (OPM Level 0 and Level 1)}

Object Process Methodology (OPM) (Dori, 2002) is a holistic, integrated approach to the study and development of systems in general and information systems in particular. The basic premise of the OPM paradigm is that objects and processes are two types of equally important classes of things. Objects are (physical or informatical) things that exist, while processes are things that transform objects. OPM provides a generic, domain independent conceptual infrastructure for modeling complex systems, which can be used for various types of projects in ALPS.

\subsection{Quality Function Deployment}

Quality function deployment (QFD) (Akao, 2004) is a method to relate the voice of customer to design and manufacturing decisions. Using QFD, ALPS teams will be able to transform customer requirements to engineering metrics and then transform engineering metrics to part characteristics.

\subsection{Prototyping Rapidly}

We ask ALPS teams to make prototypes rapidly. The purpose of making a prototype is not to show a nice-looking shape of a product, but to generate new ideas, test them and show their concepts to others or among team members in the early stage of conceptual generation. The importance of early and simple prototyping at the conceptual phase is well understood in the design community. Teams can generate new ideas by interacting with a prototype model, test their ideas by simulating its operation and discover problems which cannot be found without a prototype. They can also tell a story using a prototype.

\subsection{Infrastructure Planning}

As a system becomes larger and more complex, the appropriate design of the system depends not only on its own quality but also on the infrastructure in which the system is used. We teach ALPS students about what the needs are for the infrastructure, who stakeholders are, and how the infrastructure must be planned.

\subsection{Communicating the Proposed Idea}

We ask ALPS teams to present the idea in every workshop. We also ask them to make a one-minute video advertisement of their service or product so that they will learn how to show their idea in a very concise and clear manner. At the end of all the workshops, we ask some students to do an elevator pitch, which is a well-practiced verbal presentation of an idea in the time it would take to ride up an elevator usually in one minute. 


\section{$5 \quad$ Project Examples}

Each team identified scenarios and generated solution systems that were often unique and effective. This section describes the summary of three representative projects. Following subsections describes several proposal examples of ALPS projects with illustrations or prototypes.

\section{1. “The Power of Active Senior Life"}

The theme of ALPS 2008 was "Enhancing Senior Life". The 7-member team in ALPS 2008 observed the senior people in one region in Yokohama City and found that it was quite tough for them to drive a car and also tough to walk to bus stops even where bus transportation service was available. After they went through CVCA, morphological analysis, scenario graph, Pugh concept selection, and QFD, they proposed "The Power of Active Senior Life" with a concept of a personal vehicle "BAXI" which can be used for transportation between homes and bus stops. The illustration of BAXI is shown in Fig. 5. A team member, who was an industrial designer working for a major Japanese car manufacturer, designed the shape of this vehicle, which was very helpful for sharing ideas and presenting the concept.

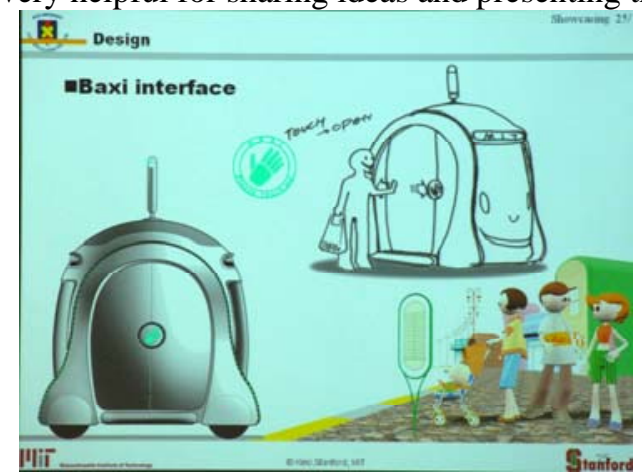

Fig. 5. Example of Prototype "BAXI" in "Enhancing Senior Life” Scenarios

\section{2. “Solar Powered Portable Refrigerator to Keep Vaccines Cool at the Time of Disaster"}

The theme of ALPS 2010 was "Safety and Security". Since 2010, the university team asked companies, government, and non-profit organizations to propose a project based on the grand theme. One of the companies that proposed a project was Infrastructure Innovation Institute, Inc. in Tokyo. The proposal was "Disaster prevention system using renewable energy". The company said that the security of energy is important at normal times as well as at the time of emergency and that they wanted a student team to propose a new use of energy at the time of emergency. After the 4-member student team did observations, interviews, several iterations of concept creations, they proposed "Solar Powered Portable Refrigerator to Keep Vaccines Cool at the Time of Disaster". They even made a working prototype using off-the-shelf 
components as shown in Fig. 6, which was very effective to show that this concept was feasible.

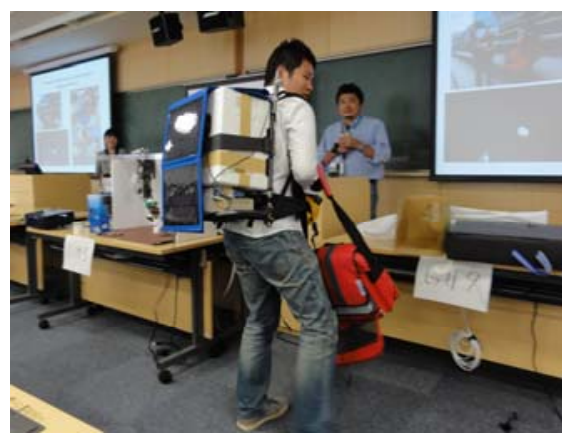

Fig. 6. Prototype of "Solar Powered Portable Refrigerator to Keep Vaccines Cool at the Time of Disaster"

\section{3. "Living and Working on a Solid Ground for Better Business Continuity”}

In the same year 2010 as in the previous subsection, another proposer company JGC Corporation, an international engineering company, proposed a project "Costeffectiveness Approach for Risk Management and Business Continuity Management" Most of the employees of JGC work in a skyscraper building in Yokohama City and if there is a disaster such as an earthquake and if the skyscraper has troubles, the company itself will not be able to continue its business, so they asked a student team to propose a unique business continuity management plan.

A 6-member student team proposed an idea of relocating employees' homes to a more solid ground called Tama Area away from Yokohama City and allow them to work at home, so that there will be less business discontinuity when there is a major disaster in Yokohama City. They made a prototype shown in Fig. 7. Interesting thing about their prototype is that they made models of "As is" and "To be" and compared them in terms of business continuity. This presentation method of comparison was a very effective way to show the superiority of the proposed idea.

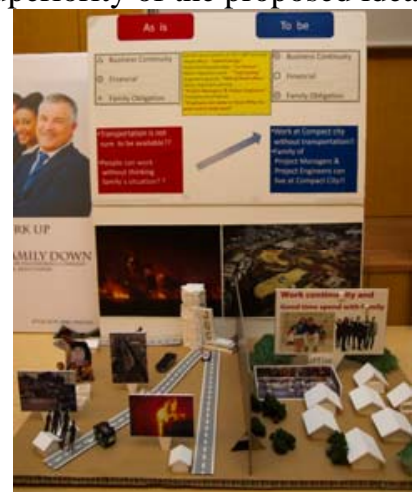

Fig. 7. Presentation using a prototype in "Safety and Security" Scenarios 


\section{Conclusion}

Keio University has been teaching ALPS since 2008 in collaboration with MIT, Stanford University, and TU Delft. We guided the System Development "V-Model," in systems engineering with design thinking methods to feel empathy for stakeholders. ALPS set a high level "Voice of Society," from which the project teams generated solution scenarios, identified specific requirements, and described the proposed system using appropriate forms of prototypes. Each year, student teams gave presentations of unique ideas for various social and technical problems proposed by companies, government, and non-profit organizations, and showed prototypes for effective communication. We are continuing this curriculum and improving our methods every year for better education of creative thinking.

\section{References}

Akao, Y. (2004), QFD: Quality Function Deployment - Integrating Customer Requirements into Product Design, Productivity Press, 1st edition, 2004

Beiter, K., Ishii, K., Karandikar, H. (2006), Customer Requirements Management: Methodology Selection and Deployment Guide, Proceedings of IDETC/CIE 2006 ASME 2006 International Design Engineering Technical Conferences, Sept. Philadelphia PA. Paper No. DETC2006-99630, ISBN 0-7918-3784-X

Brown, T. (2009), Change by Design: How Design Thinking Transforms Organizations and Inspires Innovation, HarperBusiness, New York

Czajkowski, K., Fitzgerald, S., Foster, I., Kesselman, C. (2001), Grid Information Services for Distributed Resource Sharing. In: 10th IEEE International Symposium on High Performance Distributed Computing, pp. 181-184. IEEE Press, New York.

Donaldson, K., Ishii, K., Sheppard, S. (2006), Customer Value Chain Analysis, Research in Engineering Design, Vol. 16, pp. 174-183

Dori, D. (2002), Object Process Methodology - A Holistic Systems Paradigm, Springer

Ishii, K., de Weck, O., Haruyama, S., Maeno, T., Kim, S., Fowler, W. (2009), Active Learning Project Sequence: Capstone Experience for Multi- Disciplinary System Design and Management Education, In: the 17th International Conference on Engineering Design (ICED'09), Vol. 10, pp. 57-68, California, USA

Kim, I. L., de Weck, O., Nadir, W., Young, P., Wallace, D. (2008), Innovative Modern Engineering Design and Rapid Prototyping Course: A Rewarding CAD/CAE/CAM Experience for Undergraduates, Session 332, American Society of Engineering Education (ASEE) 2004 Annual Conference \& Exposition, Salt Lake City, Utah, June 20-23, 2004

Kim, S., Ishii, K., Beiter, K. (2007), Scenario Graph: Discovering New Businesses Opportunities And Failure Modes, Proceedings of 2007 ASME IDETC/CIE Conference, September, 2007, Las Vegas, Nevada

Pugh, S. (1996), Creating Innovative Products Using Total Design: The Living Legacy of Stuart Pugh, Prentice Hall, 1996

Zwicky, F. (1969), Discovery, Invention, Research Through the Morphological Approach, Toronto, The Macmillian Company 